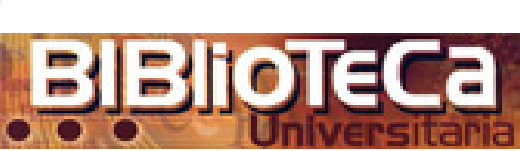

Biblioteca Universitaria

ISSN: 0187-750X

public@dgb.unam.mx

Universidad Nacional Autónoma de México

México

Ortega Muñoz, Raúl; Cañizares Alpañes, Rosa; Alfaro González, Edith; Ramírez, Roberto I. La fototeca digital: un proyecto de la Biblioteca "Manuel Sandoval Vallarta" de la Direccion General de Divulgacion de la Ciencia

Biblioteca Universitaria, vol. 17, núm. 1, enero-junio, 2014, pp. 47-54

Universidad Nacional Autónoma de México

Distrito Federal, México

Disponible en: http://www.redalyc.org/articulo.oa?id=28532369003

- Cómo citar el artículo

- Número completo

- Más información del artículo

- Página de la revista en redalyc.org

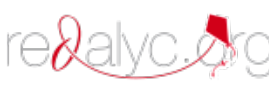

Sistema de Información Científica

Red de Revistas Científicas de América Latina, el Caribe, España y Portugal Proyecto académico sin fines de lucro, desarrollado bajo la iniciativa de acceso abierto 


\title{
La fototeca digital: un proyecto de la Biblioteca "Manuel Sandoval Vallarta" de la Dirección General de Divulgación de la Ciencia
}

\author{
A digital photo library: A project from the Library "Manuel Sandoval \\ Vallarta" of the Dirección General de la Divulgación de la Ciencia
}

\author{
Raúl Ortega Muñoz",Rosa Cañizares Alpañes ${ }^{* *}$, Edith Alfaro González ${ }^{* * *}$, \\ Roberto I. Ramírez ${ }^{* * *}$
}

\section{ReSUIIER}

Se presenta una propuesta de creación de la fototeca digital de la Biblioteca "Manuel Sandoval Vallarta", de la Dirección General de Divulgación de la Ciencia de la Universidad Nacional Autónoma de México (DGDC- UNAM). Los contenidos de dicha fototeca se refieren a temas de divulgación de las ciencias, como: mamíferos, reptiles, aves, lugares de interés, bosques, ríos, mares, y del universo como: planetas, galaxias, estrellas y sistemas planetarios, entre muchos otros; así como de las salas de los museos Universum y de la Luz. Su proceso de catalogación se lleva a cabo mediante las RCAA2 soportado por ALEPH, que le da a la base de datos de la fototeca los elementos necesarios para obtener una salida vía el OPAC en el catálogo de la Biblioteca.

PALABRAS ClaVE: Fotografía, digitalización, catalogación.

\section{Abstract}

A proposal to create a digital photo library is presented by the Library "Manuel Sandoval Vallarta" of the Dirección General de la Divulgación de la Ciencia.The contents of the photo library are related to the dissemination of the sciences, such as: mammals, reptiles, birds, attractions, forests, rivers, seas and the universe such as planets, galaxies, stars and planetary systems, among many others; as well as the rooms from the Universum and Light museums. The cataloguing process is carried out by the AACR2, supported by ALEPH, which gives the database of this library the necessary elements to be displayed via its OPAC.

KEYWORDS: photography, digitization, cataloguing

* Coordinador de la Biblioteca "Manuel Sandoval Vallarta", Dirección General de Divulgación de la Ciencia (DGDC), Universidad Nacional Autónoma de México (UNAM). Zona Cultural, Ciudad Universitaria, C.P. 04510, México, D.F., México. Correo electrónico: rortega@universum.unam.mx

** Fototeca de la Biblioteca "Manuel Sandoval Vallarta", Dirección General de Divulgación de la Ciencia (DGDC), Universidad Nacional Autónoma de México (UNAM). Zona Cultural, Ciudad Universitaria, C.P. 04510, México, D.F., México. Correo electrónico: rosicanizares@yahoo.com.mx

*** Biblioteca "Manuel Sandoval Vallarta", Dirección General de Divulgación de la Ciencia (DGDC), Universidad Nacional Autónoma de México (UNAM). Zona Cultural, Ciudad Universitaria, C.P. 04510, México, D.F., México. Correo electrónico: ealfa6@ymail.com

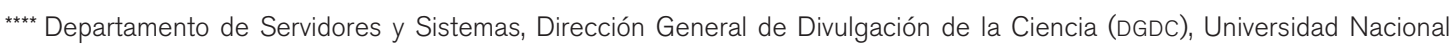
Autónoma de México (UNAM). Zona Cultural, Ciudad Universitaria, C.P. 04510, México, D.F., México. Correo electrónico: rramirez@universum.unam.mx 


\section{Introducción}

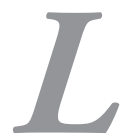

a Dirección General de Divulgación de la Ciencia de la Universidad Nacional Autónoma de México (DGDC-UNAM) transfirió su fototeca a la Biblioteca "Manuel Sandoval Vallarta" (BMSV) en junio de 2011, con el objetivo de conservar, preservar y poner a disposición de la comunidad universitaria, así como al público en general, su acervo de más de 10000 fotografías en formato analógico y digital de diferentes autores que han capturado con su lente las áreas y lugares que han visitado.

Es por ello que la Coordinación de la biblioteca se dio a la tarea de iniciar las gestiones necesarias para contar con los equipos adecuados y lograr este objetivo.

Inicialmente se contaba con una computadora MAC, un gran número de fotografías en formato analógico y las pocas que iban llegando en formato digital de los diferentes fotógrafos o de la comunidad académica.

Se hicieron las gestiones necesarias para la compra de un escáner con las especificaciones técnicas apropiadas para el cambio de analógico a digital, dando como resultado la obtención de cientos de fotografías en este último formato. Esto hace posible iniciar el proceso teniendo las herramientas necesarias para la digitalización de imágenes propias.

Para este proyecto se ha requerido tener las fotografías en formato digital, lo cual permite su fácil consulta y recuperación mediante el uso de las nuevas tecnologías.

\section{Planteamiento del problema}

Las características con que se ha concebido este proyecto son no solo el disponer de las fotografías en formatos diferentes a los actuales, como lo son los negativos, las diapositivas, las fotos impresas, sino también en formatos digitales como lo son archivos de computadora: jpg, pdf, gif o tiff, mismos que permiten la exportación y edición de las fotografías.
Una de las acciones a seguir en la integración de la fototeca en las instalaciones de la BMSV fue el determinar la manera en que se daría a conocer la información que contiene la fototeca y para ello -primeramente- el determinar qué entendemos por fotografía. Para ello se consultaron varias fuentes quedando la siguiente definición: la fotografía es el arte y la técnica para obtener imágenes duraderas debidas a la acción de la luz. Es el proceso de capturar imágenes y fijarlas en un medio material sensible a la luz; basándose en el principio de la cámara oscura se proyecta una imagen captada por un pequeño agujero sobre una superficie, de tal forma que el tamaño de la imagen queda reducido. ${ }^{1}$

Para comprender la dimensión documental de la fotografía es preciso analizar la relación que establece con la realidad, puesto que ésta es el objeto de representación, es decir, la imagen, y como tal la fotografía, siempre que se cumpla con tres preceptos:

- El modelo simbólico presente desde los orígenes de la humanidad en la utilización de la imagen como símbolo mágico o religioso.

- El modelo epistémico, según el cual la imagen aporta información (de carácter visual) sobre el mundo, cuyo conocimiento permite así abordarlo incluso en sus aspectos no visuales. Es una función general de conocimiento y la fotografía cumple de este modo una función mediadora; el fotógrafo nos sustituye -o mejor dicho nos representa- en el lugar de los hechos, sustituye a nuestros ojos e incorpora lo no vivido a nuestra memoria.

- El modelo estético, pues la imagen está destinada a complacer al espectador, a proporcionarle sensaciones especificas. Es una noción indisoluble, o casi, del arte, hasta el punto que se confunden: ¿es arte la publicidad?

LoveLL, Ronald P. Manual completo de fotografía, p. 298. 


\section{Justificación}

Actualmente la base de datos que sirve de soporte a la fototeca cuenta con 2573 fotografías, que se incrementan día a día con nuevos materiales de diversos temas como: reptiles, aves, mamiferos, Museo Universum, Museo de la Luz, planetas, entre otros; lo que hace factible que puedan recuperarse en conjunto por tema, y con ello se desplieguen para lograr una mejor difusión y beneficio de las necesiades del usuario.

Por ello se propone contar con un nuevo OPAC-Web que describa el acervo de la fototeca de una forma adecuada. (Véase cuadro 6)

\section{Metodología del trabajo}

Para el procesamiento de imágenes al principio se realizaron algunas pruebas con materiales que estaban en formato digital, pero se tuvieron problemas en la colocación de la leyenda de identificación, tamaño de la fotografía, catalogación, entre otros. Aquí es donde la Unidad de Cómputo de la DGDC apoya primeramente brindando las especificaciones del logotipo aprobado por el Consejo Asesor Interno (CAI) ${ }^{2}$ de la dependencia, y posteriormente para utilizar el escáner recientemente adquirido y poder digitalizar y cambiar el formato de las imágenes, determinando con esto las especificaciones que deben mostrar las mismas.

\section{Objetivo}

El objetivo del trabajo sobre los materiales existentes es lograr cambiar su formato de analógicos a digitales pasándolos por varios procesos con el fin de que estén dispuestos en el catálogo de la biblioteca, y con ello conservarlos y difundirlos de una mejor forma dán-

2 Consejo Asesor Interno, órgano interno de la Dirección General de Divulgación de la Ciencia, quien aprueba o declina los lineamientos y toma las directrices conforme al programa de actividades de la DGDC. doles una mayor proyección y uso a las fotografías, de manera que los usuarios obtengan la información necesaria para sus investigaciones.

Con el fin de cumplir con lo antes mencionado se abordan las diferentes fases de este proyecto:

1. Selección.

2. Digitalización.

3. Catalogación.

4. Difusión.

\section{Selección de los materiales}

La selección documental se identifica con el proceso de adquisición y se define como toda acción que tiene por objeto evaluar, discriminar y en consecuencia filtrar (escoger y/o eliminar) información en cualquiera de las fases del proceso documental. Se realizan así tres operaciones: valoración del documento, selección primaria y decisión final, únicamente con los materiales seleccionados y descartando los duplicados.

La fase de recopilación estuvo a cargo de la responsable de la fototeca, quien de forma muy sistemática ya tenía la organización de los materiales desde que se encontraban en el anterior espacio destinado a la fototeca. Esto facilitó la entrega de los mismos con número de disco, clave y nombre asignados a cada fotografía, los cuales determinan su ubicación, ejemplo:

Número de disco l.2 6/2, el sol y el sistema solar, registro de fotografía l.15 10/4

Al colocar la leyenda de identificación se recurrió a la normatividad existente, y después de varias pruebas se optó por el siguiente logotipo, en diferentes colores de acuerdo al fondo de las fotografías y se aplicó una por una. Esto trajo como resultado contar con la leyenda de identificación de la fototeca-UNAM, utilizando el logotipo de la DGDC-UNAM.

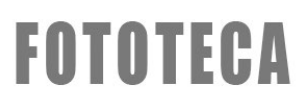
DGDC - UNAM

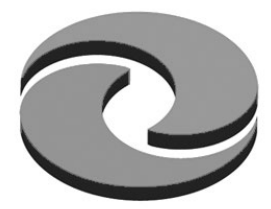


Este logotipo tiene las características de mostrarse en baja densidad con $12.0 \mathrm{k}$ pixeles/inch, con el fin de no hacerlo tan pesado; y cuando se consulte, en caso de ser útil a los fines del usuario, éste podrá solicitarlo a la fototeca directamente sujetándose a la reglamentación existente. Con estos formatos las imágenes están listas para ser subidas al catálogo y con ello a la Web.

\section{Digitalización}

Hoy las imágenes digitales, como fotografías, caricaturas y representaciones gráficas de objetos y seres vivos, son manipuladas por todos los usuarios que en su mayoría cuentan con equipos que tienen en casa. El cambio se debe a tres tendencias ocurrentes:

- La aparición de procesadores cada vez más rápidos y con mayor capacidad de resolución.

- El asentamiento de los entornos gráficos con sistemas operativos más operables.

- La tendencia generalizada de la baja en los precios de estos equipos. ${ }^{3}$

Una acertada definición de Román Gubern ${ }^{4}$ establece la imagen icónica como "una modalidad de la comunicación visual que representa de manera plástico-simbólica, sobre un soporte físico, un fragmento del entorno óptico (percepto), o reproduce una representación mental visualizable (ideoescena), o una combinación de ambos".

Si a la imagen le sumamos el calificativo de digital sólo se le confieren algunas características que hacen mención del soporte físico, donde se almacena con la forma de codificación basada en ceros y unos. En realidad, una imagen digital se compone de un conjunto de pixeles (pixel es acrónimo de PICture ELment). ${ }^{5}$

Existen variadas formas de clasificar las imágenes digitales, de acuerdo a la procedencia y a su intención de uso.

3 Hernández Pérez, Antonio. La fotografía digital. En: Documentación fotográfica, p. 205- 209.

4 Gubern, Román. La mirada opulenta: exploración de la iconósfera contemporánea.

5 Hernández Pérez, Antonio, op. cit., p. 209.
1. Imágenes generadas por computadora de forma interactiva:

a. Imágenes de arte.

b. Imágenes de diseño.

- Gráficos estadísticos.

- Gráficos de noticias.

- Gráficos de mapas.

- Gráficos de diseño industrial.

- Gráficos de entretenimiento.

2. Imágenes generadas por medios distintos a la computadora y capturadas luego mediante el uso de un escaner:
a. Imágenes de documentos impresos.
b. Imágenes de fotografías.
c. Imágenes de mediciones.

\section{Imágenes de fotografías}

Es aquí donde las imágenes de fotografías que se tienen en la fototeca de la DGDC cumplen con las características descritas, ya que por medio de un escaner pasarán a formar parte del trabajo final que implica el cambio de analógico a digital.

Inicialmente sólo se tenía el término de videos en el catálogo de la biblioteca, es por ello que en la base de datos solo existía esta liga; pero dada la necesidad de contar con una descripción más general donde se especifican los propios videos, fotografías y CD-ROMs, se tomó la decisión de colocar una nueva liga denominada Multimedios. (Cuadro 1)

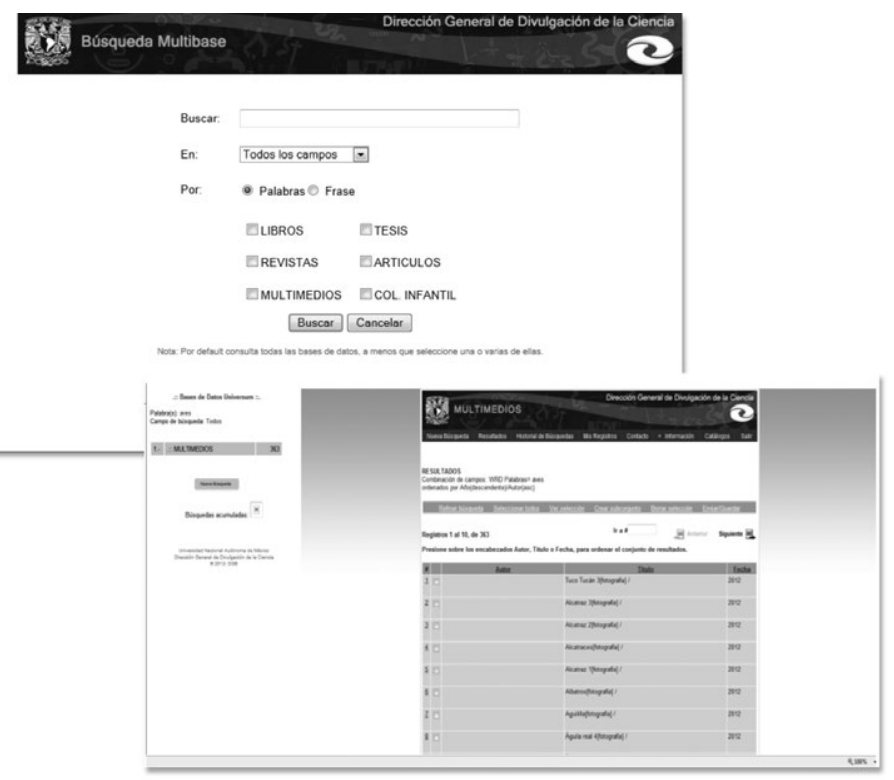

Cuadro 1. Búsqueda Multibase. Fuente: Plantilla de salida, catálogo Web-OPAC. 
Consecutivamente, el subir los archivos en Portable Document Format (PDF) al servidor de ALEPH 500 mediante el software Secure File Transfer Client (SSH) se pudo lograr la visualización de los archivos en formato PDF en el OPAC-Web de la biblioteca.

Esta página, diseñada por la Dirección General de Bibliotecas (DGB), utiliza los atributos de la parametrización que el sistema ALEPH tiene para su creación en el módulo del Online Public Access Catalog (OPAC).

Al abrir sólo el recurso de uno por uno no permite ver las otras fotografías existentes en la base.

La parte de visualización de las fotografías en el OPACWeb se hace mediante la ejecución de la liga "Ver foto" y se despliega la imagen; esto es, como bien se dijo, de una por una y no por tipo o en conjunto, que sólo se logrará manejándolas en una página web. (Cuadro 2)

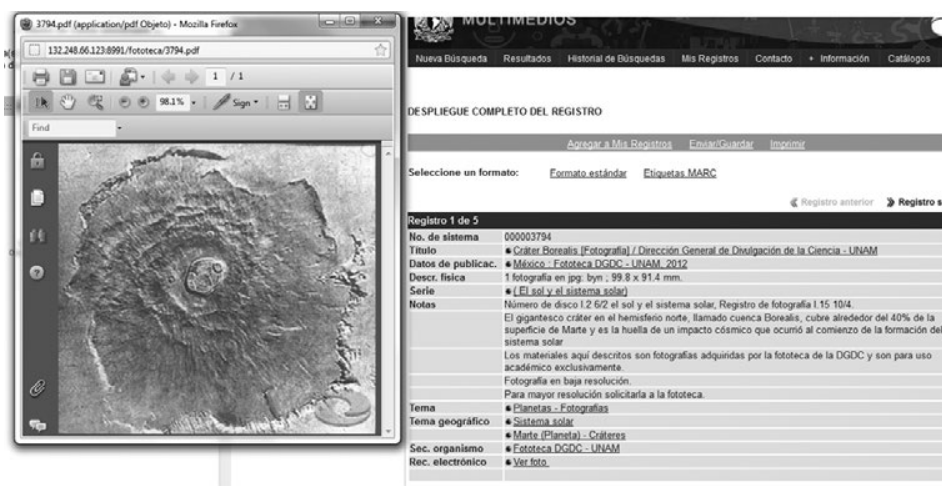

Cuadro 2. Plantilla de salida, búsqueda multibase, despliegue de foto. Fuente: Catálogo Web-OPAC de la DGDC.

Por consiguiente, esta operación deja ver un sólo registro limitando con esto la visualización de la temática buscada.

Actualmente, gracias al apoyo de la Subdirección de Informática de la Dirección General de Bibliotecas, se tiene el acceso desde la página, como se muestra en el cuadro 3. En esta pantalla la búsqueda es más fácil escogiendo una letra en el buscador, lo que proporciona resultados con rapidez.

\section{Catalogación}

Entiéndase la catalogación como el medio que sirve para identificar cada uno de los materiales que existen en la colección de la biblioteca, ya que provee datos "importantes tales como su autor, el título, otras personas que intervienen en su elaboración, el lugar de publicación y la editorial, sus características físicas (número de fotografías, tamaño, números de pixeles, etcétera), así como los temas abordados en estos materiales." 6

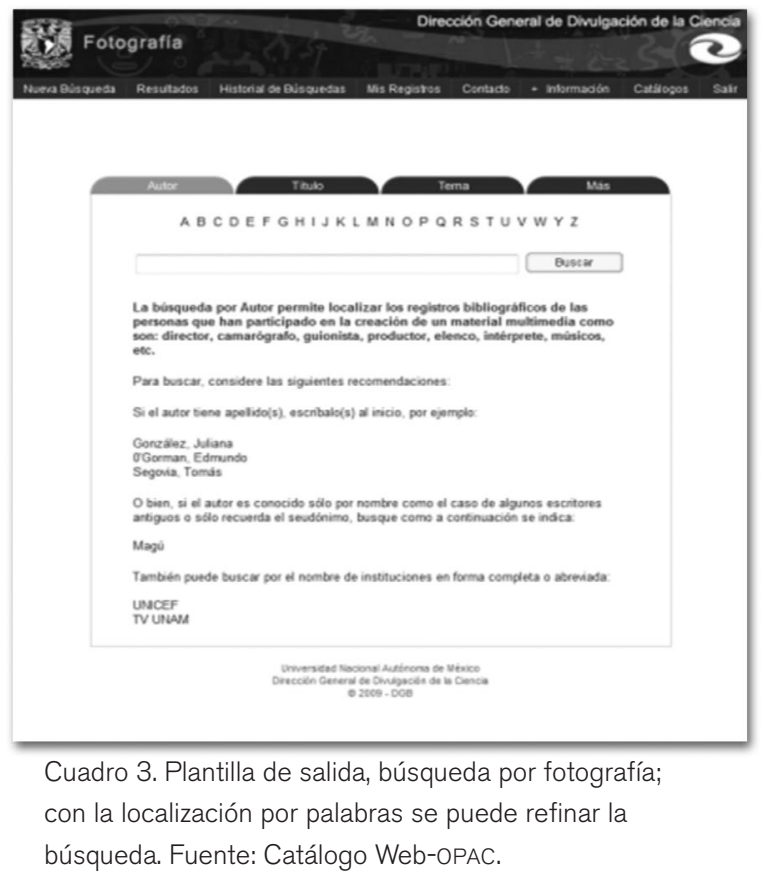

Para la organización de fotografías se utilizan los siguentes tipos de catalogación:

a. Descriptiva: tiene como finalidad la identificación y descripción de la foto para determinar los puntos de acceso o encabezamiento (excepto los de materia).

b. Temática: se realiza un análisis del contenido para determinar los tópicos principales. Para lograr lo anterior, el encargado de la catalogación debe efectuar un análisis del contenido intelectual de las fotografías, así como una

6 Martínez Arellano, Filiberto Felipe. Fundamentos de organización técnica de materiales documentales: guía de autoaprendizaje, p.32. 
búsqueda en las diversas fuentes de información (libros, enciclopedias, sitios web confiables, atlas, etcétera) que le permitan obtener conocimientos de las imágenes a catalogar. ${ }^{7}$

Conforme a lo anterior, se realizó la selección de las etiquetas del formato MARC que integran la plantilla de catalogación para la captura de información en el sistema ALEPH 500, que es el Sistema Integral para Administración de Bibliotecas utilizado por la DGDC.

La plantilla fue diseñada considerando las Reglas de Catalogación Angloamericanas en su capítulo 8, destinado a materiales fotográficos. En ella se consideró principalmente la designación general del material [fotografía], para así identificar los registros de la base denominada Multimedios.

En este proceso de catalogación se consideraron las siguientes etiquetas: (Tabla 1)
Con estos campos se integraron los registros e iniciaron las primeras catalogaciones, las cuales pueden visualizarse en el catálogo de la siguiente manera: (Cuadro 4)

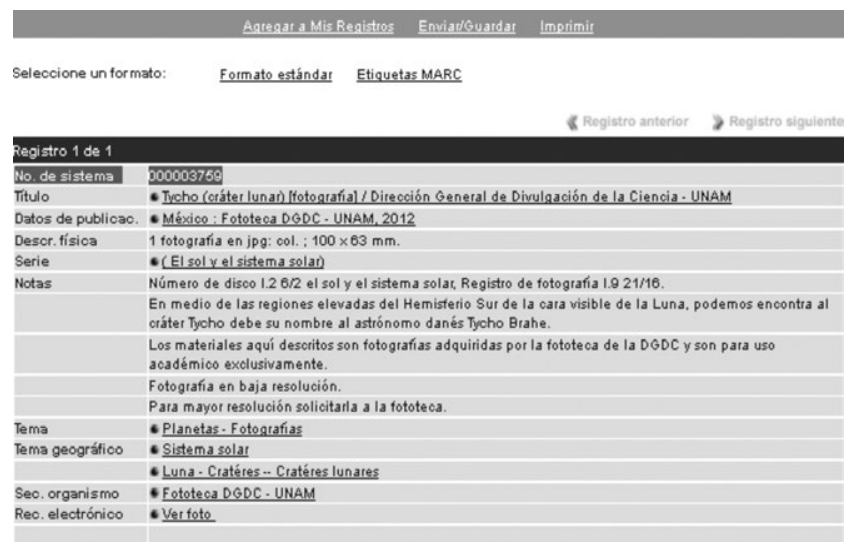

Cuadro 4. Plantilla de despliegue, formato etiquetas MARC.

Fuente: Catálogo Web -OPAC de la DGDC.

Tabla 1. Cuadro de etiquetas MARC.

\begin{tabular}{|l|l|}
\hline Campos & Descripción \\
\hline LDR & Contiene la longitud total de registros. \\
\hline 008 & Elementos de longitud fija. \\
\hline 035 & Número de control del sistema. \\
\hline 040 & Contiene los datos de la institución que hace el registro. \\
\hline 245 & $\begin{array}{l}\text { Mención de título y responsabilidad: } \\
\text { Contiene un subcampo para título (a), subtítulo (b), designación del material (h) y mención de responsabilidad (c). }\end{array}$ \\
\hline 260 & Contiene datos sobre el área de publicación y distribución de la serie. \\
\hline 300 & $\begin{array}{l}\text { Área de descripción física del material: } \\
\text { Contiene un subcampo para extensión (a), otros detalles físicos del material (b) y dimensiones (c). }\end{array}$ \\
\hline 490 & Mención de serie. \\
\hline $5 x x$ & Área de notas. \\
\hline $6 x x$ & Encabezamientos de materia. \\
\hline 710 & $\begin{array}{l}\text { Asiento secundario - nombre corporativo: } \\
\text { Contiene un subcampo para Nombre corporativo o de juridicción como elemento de entrada (a). }\end{array}$ \\
\hline 856 & $\begin{array}{l}\text { Localización y acceso electrónico: } \\
\text { Contiene un subcampo para Identificador Uniforme del Recurso ("URl") (u) y texto de vínculo (y) }\end{array}$ \\
\hline OWN & Propiedad \\
\hline SYS & Número de sistema. \\
\hline
\end{tabular}

Fuente: http://www.loc.gov/marc/bibliographic/ecbdspa.html

7 Documentación fotográfica. [Editor] Félix del Valle Gastaminza, p. 23-26. 
En la imagen siguiente se muestra el registro bibliográfico de la catalogación realizada en el módulo de catalogación del sistema ALEPH, misma que -como ya se ha mencionado- implementó la DGB con los datos aportados por los catalogadores de la DGB y la DGDC. (Cuadro 5)

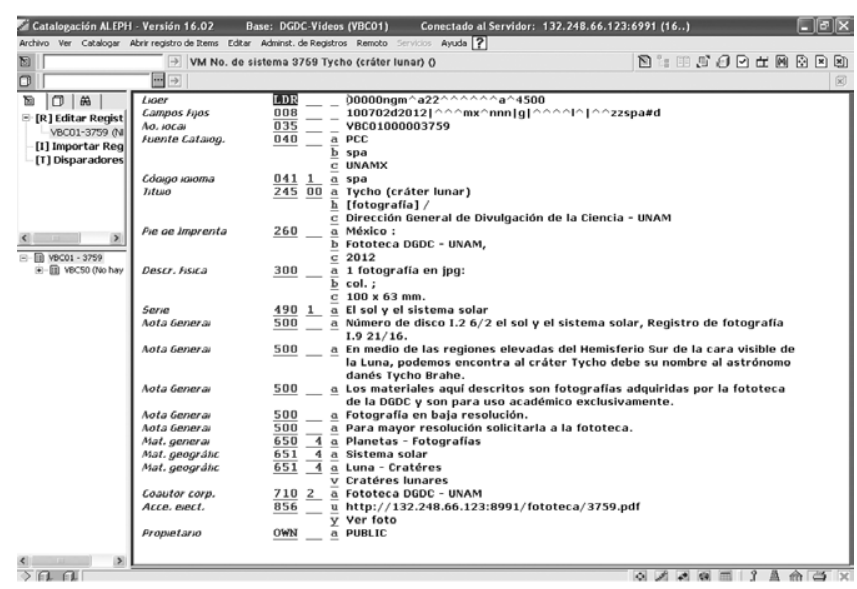

Cuadro 5. Plantilla de trabajo, catalogación local. Fuente: Módulo de catalogación ALEPH.

\section{Difusión}

Precisamente, la propuesta de acceso con la que se verían beneficiados los usuarios aquí se muestra: (Cuadro 6)

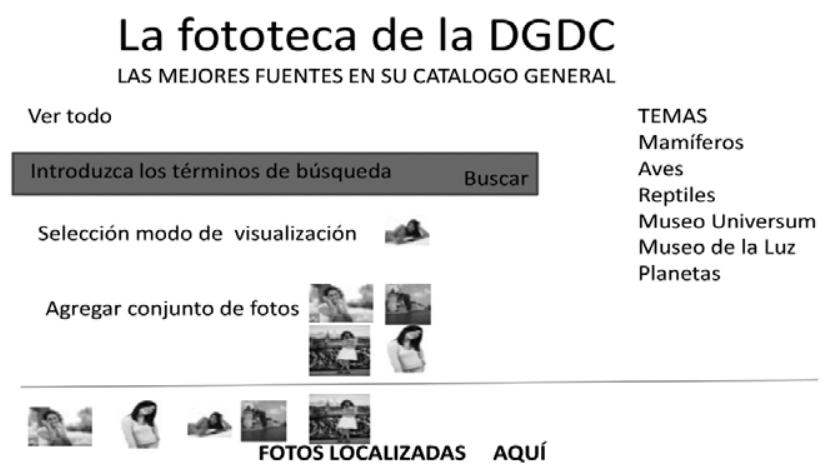

29567 Resultados de fotos [búsqueda avanzada] $1234567 \longrightarrow$

Cuadro 6. Propuesta de acceso a la liga dentro del OPAC-Web. Fuente: Elaboración propia.

Se propone contar con un nuevo OPAC-Web que describa el acervo de la fototeca de forma adecuada. Ésta formaría parte de la página web de la biblioteca, así se tendrían dos formas de acceder al producto: desde la página a la liga de la Fototeca o a través del catálogo, dependiendo de la búsqueda Multibase o Fotografía.

Con esta sencilla liga a la página se puede tener la posibilidad de ofrecer a los usuarios que consulten la fototeca un recurso adicional al catálogo que ofrece la DGB, ya que permitiria obtener de forma rápida $\mathrm{Ver}$ todo lo existente en la base. Por Temas, en esta liga muestra la información de acuerdo a la catalogación de temas, por ejemplo: mamíferos, aves, planetas.

\section{Conclusión}

La conjunción de los profesionales de la bibliotecología y del profesional del archivo de la fototeca, así como el apoyo de las áreas de cómputo de la DGDC y de la DGB, ha sido de vital importancia para la Fototeca, ya que sin ellos no se podrían brindar adecuadamente la exposición y la disposición de los archivos fotográficos. El acceso a la página web de la Fototeca ofrece una gama de posibilidades y la oportunidad de visualizar -y con ello escoger- la información adecuada a las características del trabajo en cuestión, dando como resultado contar con una herramienta de consulta para que los usuarios, tanto los internos como los externos, tengan la posibilidad de utilizar este nuevo recurso en la Biblioteca "Manuel Sandoval Vallarta", logrando que sea una de las primeras en mostrar su acervo fotográfico, y -por otro lado- compartir su experiencia con el Sistema Bibliotecario y de Información de la Universidad Nacional Autónoma de México.

El haber desarrollado la base de datos Multimedios/ Fotografía con el Sistema ALEPH 500 garantiza que la información cumpla con los estándares internacionales como MARC21, además de que posibilita ampliamente en un futuro poder trasladar o migrar de plataforma. cos

Este recurso se encuentra ya disponible para todo público en la liga: http://biblioteca.universum.unam.mx 


\section{Obras consultadas}

AguAYO, Fernando, RocA, Lourdes. Imágenes e investigación social [en línea]: estudio introductorio. <http://durito. nongnu.org/docs/Aguayo_Roca_2.html> [Consulta: 6 agosto 2012].

Aguayo, Fernando, Green, Andrew, Roca, Lourdes. Proyecto de investigación para la creación de una fototeca digital y un sistema de información para archivos fotográficos (SIAF) [en línea]. Anais do Museu Paulista, jan.-jun. 2005, vol. 13, no. 1, p. 235-252. <http://www.redalyc.org/articulo.oa?id=27313108> [Consulta: 6 agosto 2012].

Barra Moulain, Paula Alicia. Normas catalográficas del Sistema Nacional de Fototecas del INAH. México, D.F.: Instituto Nacional de Antropología e Historia, 2005. 45 p.

BYRNE, Deborah J. Manual de MARC: cómo interpretar y usar registros MARC. Buenos Aires: GREBYD, 2001. 270 p.

Caravia, Santiago. La Biblioteca y su organización. Gijon, Espańa: Trea, 1995. 198 p.

Catalogación de documentos: teoría y práctica. Editora María Pinto Molina. 2a ed., rev. y actualizada. Madrid: Síntesis, 2001. 495 p.

Chacón Alvarado, Lucía. Automatización de la biblioteca. San José, Costa Rica: Universidad Estatal a Distancia, 1996. 166 p.

Documentación fotográfica. [Editor] Félix del Valle Gastaminza. Madrid: Síntesis, [1999?]. 255 p.

Gómez-Díaz, Raquel, Gómez Isla, José, CordónGarcía, José-Antonio, Domínguez López, Juan José. El patrimonio fotográfico de la Universidad de Salamanca: la creación de una fototeca digital. Journal Article (Print/Paginated) Ibersid, 2007, p. 177-194.
Green, Andrew Rusell. Cambios actuales en el esquema de supuestos básicos de las prácticas catalográficas [en línea]. <http://www.nongnu.org/durito/ docs/cambios_catalog_green.pdf> [Consulta: 6 agosto 2012].

Gubern, Román. La mirada opulenta: exploración de la iconósfera contemporánea. Gustavo Gili: Barcelona, 1987. $426 \mathrm{p}$.

Hernández PÉrez, Antonio. La fotografía digital. En: Documentación fotográfica. [Editor] Félix del Valle Gastaminza. Madrid: Síntesis, [1999?], p. 205- 209.

Lafuente López, Ramiro, Garduño Vera, Roberto. Lenguajes de marcado de documentos digitales de carácter bibliográfico. México: unam, Centro Universitario de Investigaciones Bibliotecológicas, 2001. $280 \mathrm{p}$.

Lovell, Ronald P. Manual completo de fotografia. Madrid: Celeste, 1998.398 p.

Martínez Arellano, Filiberto Felipe. Fundamentos de organización técnica de materiales documentales: guía de autoaprendizaje. México: Escuela Nacional de Biblioteconomía y Archivonomía, 1997. 121 p.

Reglas de Catalogación Angloamericanas. 2a ed., revisión de 2002, actualización de 2003. Bogotá, D.C: Colombia: R. Eberhard, 2004. 1 v. en varias paginaciones.

Sanchez Luna, Blanca Estela. Organización bibliográfica de materiales audiovisuales. México: UNAM, 2006. 